\title{
CIBER(DES)CORTESÍA EN LOS FOROS DE OPINIÓN DE LA PRENSA ESCRITA: UN EJEMPLO
}

\author{
Ana María Vigara Tauste \\ María ISABEl HeRnÁNDEZ Toribio \\ Universidad Complutense de Madrid \\ amvigara@ccinf.ucm.es \\ ihtor@ccinf.ucm.es
}

\begin{abstract}
Resumen
Como es sabido, la prensa escrita ha experimentado, con la llegada de internet, un notable cambio en la relación con sus lectores, que, con frecuencia, pueden expresar libre y públicamente su opinión sobre lo leído (o cualquier otra cosa) en los foros ("bancos de opinión") habilitados para ello. En este tipo de interacción, el opinante que escribe y envía su mensaje puede (y suele) mantenerse simultáneamente activo en al menos tres instancias de enunciación diferentes: a) comunicación con el periódico (se pronuncia sobre los contenidos de la noticia); b) con el público del periódico (potenciales lectores de su comentario); c) con el resto de los lectores del foro (que pueden, a su vez, dar la réplica a cualquier intervención previa).

Intentaremos analizar, en un ejemplo concreto (acontecimiento deportivo publicado en el periódico La Vanguardia), los actos de (des)cortesía que surgen en estas diferentes instancias enunciativas, para lo cual prestaremos atención tanto a las simples intervenciones como a las réplicas generadas a partir de ellas.
\end{abstract}

PALABRAS CLAVE: foros, foros de opinión, ciber(des)cortesía, prensa escrita, fútbol.

\begin{abstract}
As it is well known, the arrival of Internet has caused a big change in the way that newspapers relate to their readers, who are able now (openly and freely) to express their opinion (related to what they have read, or anything else) in the forums (opinion databases) intended for that purpose. In this kind of interaction, any person giving an opinion, writing and sending his/her message, may be (and frequently is) active in at least three different enunciation levels: a) communication with the newspaper (giving an opinion about the content of an information), b) with the public of that paper (potential readers of his/her comment); c) with other readers taking part in the forum (who, in turn, can answer any previous message). We shall analyze, with a given example (a sports event published in the newspaper La Vanguardia) the (im)polite acts that appear in these different enunciation instances. To do so, we will focus both on the messages and the answers generated after them.
\end{abstract}

KEY WORDS: Key words: forums, opinion forums, cyber(im)politeness, opinion, press

\section{Introducción}

La prensa escrita ha experimentado, con la llegada de internet, un notable cambio en la relación con sus lectores. Y una buena muestra de ello lo consti- 
tuyen los foros (o "bancos de opinión"), donde estos pueden expresarse públicamente. De este modo, la prensa no solo "informa", sino que implica a sus lectores permitiéndoles opinar; es decir, incentivando su participación en espacios (falsamente interactivos) habilitados al efecto.

Por su parte, los lectores saben que pueden exponer su opinión, pero son conscientes también de que, en principio, esta, que se expresa a posteriori y sobre lo ya publicado, suele ser de hecho intrascendente para el propio periódico que les ha cedido la tribuna. Éste no tiene por qué hacerse eco de las opiniones de sus lectores ${ }^{1}$, aunque con frecuencia utiliza para su propia promoción los datos de participación en estos foros.

Como veremos en un ejemplo concreto, el foro de opinión se convierte en un espacio de interacción múltiple, no solo con el propio periódico, sino fundamentalmente entre los distintos usuarios. Traspasa, por tanto, las fronteras de la información ofrecida por el periódico, que suele ser (pero no necesariamente, como se verá) la que da lugar a las correspondientes intervenciones de los participantes.

\section{Discurso y (des)cortesía en los foros de opinión}

En los foros de opinión, los participantes están unidos por un objetivo (opinar) y una excusa (la noticia del periódico) comunes. El propio acto social de comunicación, constituido en "foro de opinión", actúa como contexto global suficiente para que esta sea efectiva. Y en virtud de la co-intención y del acuerdo comunicativo entre autor y lector, ambos "se encuentran en una situación que los obliga a suscribir, previamente a toda intención y estrategia particular, un contrato de reconocimiento de las condiciones de realización del tipo de intercambio lingüístico que llevan a cabo" (Charaudeau, 2003: 78).

Sería absurdo pensar que la aparición de los distintos fenómenos de (des)cortesía y de lenguaje en un acto comunicativo atañe solo a los sujetos participantes, como si estos, una vez suscrito el correspondiente "contrato" de reconocimiento de las condiciones de su comunicación particular, actuaran abstraídos de tales condiciones o al margen de ellas. Todo lo contrario: género discursivo y condicionantes del registro son, sin duda, además de ineludibles para los hablantes (locutores, escritores), dos de los principales factores a los cuales adaptan y adecuan su actuación comunicativa (el otro es el interlocutor).

$1 \quad$ La sección de "Cartas al director" tiene esa función y, en ella, las cartas de los lectores previamente seleccionadas y corregidas (a veces incluso abreviadas si fuera necesario), se publican como parte del propio periódico. 
Veamos, pues, las principales características del género discursivo que aquí nos interesa (opinión en foros) y los condicionantes que influyen en el comportamiento comunicativo y social de los participantes, puesto que todos propician la aparición de ciertos fenómenos de (des)cortesía y de lenguaje en ellos.

\subsection{Los foros y los foros de opinión}

En principio, hay que puntualizar que los que hemos denominado foros de opinión no son exactamente "foros", aunque sí se expresan en ellos "opiniones", palabra esta con la que además denomina el propio periódico a ese espacio que reserva al final de cada noticia para sus lectores.

Como los foros propiamente dichos, las "opiniones" de los lectores de los periódicos son manifestaciones discursivas que tienen su soporte en las llamadas TIC (Tecnologías de la Información y la Comunicación)²: aparecen en espacios institucionalizados para el intercambio y debemos estudiarlos como "textos" que forman parte, con otros similares, de un macroacto comunicativo que los engloba y en el que adquieren sentido.

Sin embargo, frente a los foros propiamente dichos, que se activan con un propósito-tema que se enuncia en el título y condiciona la participación en ellos y que suelen contar con un gestor (y filtrador) de contenidos y formas de expresión, en los foros de opinión el opinante no está, en principio, condicionado por un tópico particular y su texto, normalmente, "sube" sin muchos filtros a la red una vez enviado ${ }^{3}$.

Si bien la aparición de una noticia suele actuar como tópico de encuentro para los participantes, esta se convierte, con frecuencia, en una mera excusa para opinar. De manera que si, en un principio, el lector puede -y suele- opinar sobre la objetividad o la veracidad de la noticia, la (im)parcialidad del medio, la idoneidad de la publicación o de lo publicado, etc., es muy frecuente que enseguida el foro se convierta en el soporte al que se llevan las opiniones personales, los prejuicios, las creencias, las rivalidades sociales previas...

Se da por descontado que opinar libremente es lo que se supone que hay que hacer en los foros, así que, por principio, discrepar no es (no puede ser) descortesía, y menos en un foro de opinión, en el que el objetivo es precisamente someter algo concreto (una noticia, en nuestro caso) a juicio público. Se entiende así que en estos textos se encuentren en general más críticas negativas que positivas, más rasgos de descortesía (o quizá de "neutralidad") que de cor-

2 También los chats, los blogs y los correos electrónicos.

3 Así al menos nos ha parecido personalmente. Siempre que hemos probado a participar en ello hemos visto cómo nuestro comentario aparecía inmediatamente publicado. 
tesía; que en general se manifiesten e importen más y mejor las "relaciones" de afiliación/autonomía que las estrategias de imagen ( face); y que esto ocurra en las tres instancias de enunciación diferentes en las que los opinantes se mantienen simultáneamente activos:

a) comunicación con el periódico (se pronuncian -o no-sobre el contenido de la noticia publicada, su importancia, la idoneidad de su publicación, etc.);

b) con el público del periódico (potenciales lectores de su comentario);

c) con el resto de lectores del foro (que pueden, a su vez, dar réplica a cualquier intervención previa).

Foros (propiamente dichos) y foros de opinión comparten, además de su adscripción a las TIC, otras semejanzas y diferencias que nos interesan mucho aquí porque nos dan algunas de las más importantes claves de interpretaciónanálisis de estas manifestaciones discursivas ${ }^{4}$. Veámoslas.

\subsection{La comunicación mediada y su influencia sobre el discurso}

Explica Kress (2005) que la mediación tecnológica (que incluye en su origen oralidad, escritura e imagen) incide en tres de los aspectos en que se desarrolla la noción de interactividad:

a) El interpersonal: la comunicación escrita habitual es unidireccional y diferida, pero se convierte en bidireccional, cercana y bastante inmediata cuando se utilizan las herramientas tecnológicas para su producción-transmisión.

b) El de intertextualidad: hay que tener en cuenta la proliferación de textos y la capacidad para el almacenamiento, recuperación y relación entre ellos que se proporciona a los usuarios.

c) El de inestabilidad del texto y de la noción de autor (con la consiguiente pérdida de autoridad y de poder).

Visto desde el lado de la transmisión (que es la instancia en que actúan primordialmente las tecnologías y a la que se subordinan las de producción e interpretación), en lo que influye la mediación tecnológica es esencialmente en la configuración del contacto entre los comunicantes.

Más allá de la noción de canal (con el que aludimos al uso del medio físico de transmisión), entendemos contacto como la conexión psicológica establecida y "viva" entre quienes participan en la comunicación. Canal y contacto van de la mano en la comunicación oral, pero en la escrita experimentan distintos grados de disociación tanto en la fase de producción como en las de

4 Los efectos de la mediación tecnológica en el uso pragmático del lenguaje están estudiados en Vigara (2004) y Yus (2010). 
transmisión y recepción del mensaje (es decir, en el proceso completo de la comunicación).

En lo que al manejo del canal se refiere, las "opiniones" comparten con los foros las mismas condiciones de actualización del mensaje:

a) el locutor produce (y concibe) éste desde la escritura;

b) la comunicación es, por tanto, diferida,

c) en ambos casos está, por añadidura, mediada por la tecnología.

El proceso vivo del contacto, sin embargo, difiere en no pocos aspectos de la comunicación escrita (tradicional). En la comunicación mediada por las TIC, la "coespacialidad" de la pantalla sitúa en realidad al locutor (o emisor) en una ilusoria (pero psicológicamente efectiva) "copresencia" del otro, no geográfica ni espacial, sino temporal-vivida. De este modo, en nuestros foros de opinión (y frente a lo que ocurre, por ejemplo, en los textos literarios) la comunicación diferida va más allá de la pura dilatación temporal entre la emisión y la recepción: realiza una peculiar disociación de los elementos básicos de la transmisión (del canal y el contacto) y, con ellos, de los agentes de la producción-interpretación: el emisor y el receptor (el plano interpersonal del que habla Kress, 2005).

En general, la mediación de la tecnología borra las fronteras del espacio y el tiempo, difumina la responsabilidad de emisor y/o receptor respecto del mensaje, abrevia los plazos de emisión-recepción, ofrece un potencial de comunicación, en teoría, infinito y proporciona la impresión de co-temporalidad y retroalimentación (es decir, inter-locución) constante entre los usuarios, que son, en el caso de los foros de opinión, anónimos los unos para los otros.

Y todo esto tiene reflejo, lógicamente, en las estrategias lingüísticas de (des)cortesía que podemos encontrar en ellos, pues propicia una remodelación del yo que se comunica, de sus relaciones con los demás y de la reciprocidad de tales relaciones. (Lo veremos en el siguiente apartado y en el análisis concreto que del comportamiento [des]cortés de los opinantes con otros participantes en el foro hacemos en la segunda parte de este trabajo.)

\subsection{Condicionantes de la comunicación mediada en los foros de opinión (oralidad, escritura)}

Básicamente, lo que encontramos en los foros de opinión son una serie de textos que corresponden a intervenciones diferentes de personas distintas y que adquieren sentido en el marco del conjunto. Como suele ocurrir, en los textos (y en estos en particular) encontramos numerosos rastros de las cosas que han acontecido en la interacción y también, desde luego, de las condiciones que la comunicación mediada les "impone". 
Aunque suele hablarse de ciberconversaciones para aludir tanto a los foros como a los chats, se ha convertido en un tópico decir que estas muestran, por la premura e inmediatez con que suelen realizarse, numerosos rasgos de oralidad. Pero lo cierto es que estas "ciberconversaciones" constituyen esencialmente escritura (para la comunicación) mediada. Aunque los rasgos de "informalidad" pueden ser (o no) muchos en ellas, los de oralidad propiamente dicha son muy escasos (más aún en los foros que en los chats ${ }^{5}$ ). Pero nótese que, frente a lo que ocurre en los actos orales de comunicación, en los escritos en general y en los de los foros en particular, no asistimos, aunque quisiéramos, al proceso "vivo" en que se produce el mensaje: solo podemos observar su resultado; es decir, los propios textos fijados en el soporte informático.

Para los foros -ya lo hemos dicho- el mensaje está concebido y producido desde la escritura (no desde la oralidad). Y aunque, gracias a la mediación tecnológica, la escritura que encontramos en foros y opiniones puede recibir retroalimentación de otros potenciales receptores-locutores (como ocurre en la oralidad), lo cierto es que, frente a lo que sucede también en esta, los autores de los textos no precisan actualizar en su mensaje el contexto real "actual" para el otro; ni tampoco, frente a lo que ocurre en la escritura (no mediada), proporcionarle todos los datos contextuales al lector en su mensaje para que este pueda interpretarlo adecuadamente, pues es el propio acto de comunicación social ("foro de opinión") el que actúa de contexto global suficiente en la comunicación.

Aunque está concebido desde la escritura y condicionado, como ella, por la linealidad espacio-temporal, el mensaje-texto que se produce para los foros de opinión no presenta voluntad de perpetuación ni suele pretender trascendencia especial alguna. Y esto, sin duda, lo comparte con la oralidad prototípica. Pero, frente a lo que ocurre en esta, en los foros el mensaje queda, como la escritura, fijado en un soporte material, aunque efimero; y efímero no tanto porque los textos desaparezcan rápidamente y dejen de estar accesibles, cuanto porque, ligados a la noticia y el resto de intervenciones que los han hecho posibles, dejan de suscitar interés (y, por tanto, de ser leídos) cuando estas pierden actualidad.

El hecho de que la opinión vaya a quedar fijada en un soporte material y de que sea el opinante quien decide cómo y cuándo hacer llegar su texto hasta el espacio virtual que le dará cobijo significa que, en principio, el hablante dispone de tanto tiempo como desee/precise para elaborar, releer y hasta corregir, si

5 Inglés chat 'conversación'. Podemos adelantar ya algo también esencial que necesariamente alcanzará reflejo en las distintas manifestaciones: mientras que los chats se instituyen como "habla privada" (aunque se ejerza con desconocidos a veces), los foros constituyen, por definición, "habla pública". 
lo desea, su mensaje. Salvo excepciones, el autor de estos textos de opinión no está condicionado por la inmediatez interlocutiva (que es característicamente oral); lo estará, si acaso, por la actualidad y corta vida de la noticia o de los contenidos que se intercambian en el foro, pero esto, presumiblemente, influirá algo en lo que dice y poco o muy poco en la forma en que lo dice. Así pues, podemos suponer, razonablemente, que si aparecen rasgos de (des)cortesía discursiva o de descuido formal en estas opiniones, serán más bien achacables a características o reacciones del sujeto emisor que a condicionantes del registro. De hecho, entre las opiniones encontramos algunas escritas con gran corrección grafonómica y gramatical:

(1) Vergüenzaajena | 21/02/2008, 22:49|BCN |

jsorel: vas de listo, pero lo que eres es un listillo. Todos (menos tú) saben que el equipo de Luis, y de toda su familia, es el madrit, aunque luego le tocó jugar en el Atleti. ¿No lo sabías? pues TOMA NOTA. ¿O es que crees que el equipo de Zubi es el Barça? NO: es y siempre será el Athletic. Pero son profesionales, no lo olvidemos. Raúl no debió jugar cuando estuvo pasando aquel bache, y fue porque los periodistas de la capital son unos arrogantes y machacones. Y ahora lo está purgando 6 .

Pero podemos encontrar otras que parecen escritas de forma apresurada e incumplen abiertamente las convenciones más elementales de la lengua escrita, como en el ejemplo 2 , sin puntuación de ningún tipo, ni tildes ni mayúsculas diacríticas:

(2) flora | 21/02/2008, 18:31 | [17]

empieza la campaña y a politizar el futbol que se cre raulito simbolo de que de la zorreria como butragueño los poderosos de que amasar fortunas y por eso les apoyan los derechistas

$\mathrm{Si}$, pese a todo, la comunicación funciona y el lector entiende globalmente que "flora" está en contra de "raulito", de "butragueño" y de quienes los apoyan a ellos y a su equipo, es precisamente porque -como hemos explicado-el contexto del propio acto comunicativo (foro de opinión sobre una noticia concreta), compartido por autores y lectores, es lo suficientemente informativo como para permitir una adecuada interpretación. Y esto es así aunque al pare-

6 Una lectura atenta nos permite apreciar que construye bien las oraciones, articula bien sus argumentos, utiliza perfectamente las tildes y con bastante corrección los signos de puntuación. Podríamos comentar algunos detalles, pero son pocos (cuatro), alguno intencionalmente estilístico (el madrit: nombre propio del equipo rival, en minúscula y escrito "según las pronunciación a la catalana", con -t, frente al equipo propio, en mayúscula: $e l$ Barça), y todos de muy poca importancia (olvido del punto final; minúscula después de punto en "¿No lo sabías? pues TOMA NOTA"), empleo de versales para dar relieve a algunos puntos (TOMA NOTA; NO), algo que, de acuerdo con las normas de netiqueta, significa "grito"), o incluso justificables (jsorel ha escrito su nombre-apodo así, en minúscula, y así lo reproduce): se trata, sin duda, de un/a hablante culto/a. 
cer "flora" se ha expresado de forma "descuidada" (que quizá podríamos llamar también "informal") y por simple aproximación (algo típico de la lengua oral), y aunque no contemos ni con las convenciones de lectura de la lengua escrita ni con la ayuda del paralenguaje de la lengua hablada.

En semejantes condiciones, y puesto que de todos modos el mensaje "se entiende" y esto puede ser suficiente para los objetivos de los comunicantes, es probable que (como ocurre, por otra parte, en la comunicación oral) la exactitud y la propiedad no formen parte de los intereses comunicativos de los autores y que, aunque estos disponen de tiempo para elaborar su mensaje, la mayoría no se planteen siquiera utilizar ese tiempo para corregirlo y perfeccionarlo, no sientan la necesidad de hacerlo. Pero ello no quiere decir, obviamente, que ese "descuido" haya que interpretarlo como un rasgo de oralidad.

Lo que aparece en las "opiniones" es, en definitiva, habla pública (en soporte escrito: escritura mediada), pero efímera y sin consecuencias, y monogestionada, pero dialógica (lo cual no quiere decir que sea "conversacional" ni "coloquial", que no lo es).

3. Ciber(des)cortesía en los foros de opinión: "Luis Aragonés y Raúl sellan la paz a petición del futbolista" (lavanguardia.es, 22 febrero 2008)

Seguramente, si hay un tema que nos permita comprobar cómo el foro del periódico se convierte en el soporte al que se llevan las opiniones personales, los prejuicios, las creencias, las rivalidades sociales previas..., traspasando así el interés de la noticia que lo ha desencadenado, y cómo la comunicación mediada influye de forma decisiva en la expresión de las estrategias de imagen de los participantes, ese es, sin duda, el del fútbol y la rivalidad futbolística, que suscita siempre muchos comentarios en internet.

Para verificar todo esto, hemos analizado las opiniones de un foro en $\mathrm{La}$ Vanguardia (lavanguardia.es) sobre una noticia que tuvo en su momento bastante eco en los medios y entre el público: la "reconciliación" pública de Raúl González, jugador del Real Madrid, y Luis Aragonés, entonces entrenador de la selección nacional de fútbol; ambos -se decía- tenían mala relación: el uno porque el seleccionador lo dejaba en el banquillo; el otro porque se sentía presionado por Raúl, "su entorno" y los propios medios de comunicación ${ }^{7}$.

\subsection{La noticia de referencia y sus protagonistas: imagen pública vs imagen personal}

Como es sabido, todo acto comunicativo se inserta en un determinado contexto sociocultural, en el cual adquiere pleno sentido.

7 http://www.lavanguardia.com/deportes/20080221/53439101967/luis-aragones-y-raulsellan-la-paz-a-petición-del-futbolista.htm 
Los contextos socioculturales son -en palabras de Diana Bravo, 1999: 157) - "contextos específicos que abarcan comportamientos, actitudes y valores que son conocidos, aceptados y practicados en una comunidad de hablantes". Las características concretas de estos contextos, a su vez, "están relacionadas con los deseos de imagen de los hablantes, los cuales pueden incluirse en dos categorías generales: imagen de autonomía e imagen de afiliación" (ibídem).

En el caso que nos ocupa, son precisamente los respectivos sentimientos/ comportamientos de autonomía y afiliación o la repercusión pública que estos tienen, sobre todo a través de los medios, los que mueven a los protagonistas (futbolista y seleccionador) a convocar "una conferencia de prensa conjunta" en la que hacer ver a todos que definitivamente "sellan la paz": a los periodistas, en directo; al público lector (y, en última instancia, al aficionado y al público en general), por mediación de los periodistas y de la versión que estos den luego en sus medios de lo dicho y hecho allí.

Tanto Raúl González como Luis Aragonés se expresan con plena conciencia, al parecer, de estar "actuando" públicamente y para otros (sobre algo ya previamente acordado entre los dos). Se trata, sobre todo, de acallar los debates públicos, las murmuraciones. Y hasta tal punto se trata sobre todo de eso, de contárselo conjuntamente a la prensa (para que esta lo difunda), que basta con leer entre líneas en la información para darse cuenta de que, en lo esencial, ninguno de los dos ha cambiado su posición personal al respecto ni está dispuesto a transmitir esa impresión. Lo que encontramos es un juego continuo de tiras y aflojas, estrategias sucesivas de afiliación-pero-autonomía (o de autonomía-pero-afiliación, si se quiere) que, sin hacer ni haber hecho ni pretender hacer en el futuro cambios en lo esencial, se utilizan para dar voz pública a esa "paz" en el mundo del espectáculo deportivo. Para contribuir a esa deseable imagen personal ("positiva" o "negativa") y pública de afiliación y acuerdo surgen las apreciaciones positivas y los elogios (indirectos siempre, expresados en tercera persona, para los periodistas), con los que se reconoce algún mérito o cualidad en el otro:

Para Luis Aragonés, es esencial preservar su imagen negativa (face), dejar claro que no ha aceptado ni aceptará ningún tipo de presión como seleccionador (la alusión a la "bajada de pantalones" no es casual). Para Raúl González es más importante, en cambio, preservar su imagen positiva, que quede claro para todos su lealtad para con la selección y su acatamiento de las decisiones del seleccionador, que es, en última instancia, en quien debe reconocerse la autoridad.

(3) Luis Aragonés dice que el "comportamiento de Raúl" con él ha sido "extraordinario" 
(4) Raúl, por su parte, asegura: "En el tiempo que he estado a su cargo lo único que puedo decir es que las cosas han ido bien".

Aunque se trata de comentarios positivos ${ }^{8}$, se encuentran, como puede apreciarse, lejos del halago personal (obsérvense los sujetos "objetivadores" de los respectivos enunciados: "el comportamiento de Raúl" y "las cosas") y, desde luego, de la adulación, actos que sin duda ambos evitan, pues pueden resultar un auténtico regalo verbal "envenenado". No olvidemos que quien recibe un halago puede -dependiendo del contexto- situarse en posición de deudor respecto a quien lo ha realizado (Kerbrat-Orecchioni, 2001: 77).

La mayor parte de su esfuerzo se centra, por el contrario, en la autoafirmación de su imagen (personal, social) de autonomía. Ambos reconocen explícitamente que lo importante no es que la gente esté equivocada, sino que la prensa colabore en sus objetivos ("Lo importante es que se acaben todos los debates"); Raúl reconoce que ha habido malentendidos previos ("Está claro que en la relación entre técnico y jugadores siempre hay malentendidos, pero [...]"); Aragonés reafirma y reitera su opinión, sus formas de actuar y pensar previas a la propia reunión, en una clara actividad de autoimagen frente a las críticas que ha recibido durante mucho tiempo por no convocar al jugador para los encuentros ("Si considero que debo convocarlo, lo haré y si considero que no, no lo haré"; "Aragonés [...] ha afirmado que él no se 'baja los pantalones' ni cuando se quita el cinturón"; "El seleccionador ha recordado que el incidente del último partido de la selección en Málaga [...] fue preparado. 'Pero no por Raúl ni por su entorno, aunque no voy a decir por quién'”).

En términos generales, la posición personal de los protagonistas (el uno con respecto al otro y ambos respecto de lo ocurrido) no ha cambiado ni va a cambiar tras este encuentro (hecho a petición del jugador), en el que, inevitablemente, está también implicada su imagen personal (face). En la imagen pública que proyectan en esta conferencia de prensa conjunta se adivina que es Raúl, que ha tomado la iniciativa (y probablemente sufre más con la situación, pues depende, en todo caso, del seleccionador), quien está más interesado en dar voz a sus sentimientos/deseos (imagen) de afiliación, y Aragonés quien más se esfuerza en dejar clara su autonomía e independencia, pese a todo.

Por supuesto, a esta operación de imagen y a la propia imagen pública de los protagonistas aluden con frecuencia los opinantes del foro, unas veces como cen-

8 El cumplido pretende crear un ambiente de amabilidad, expresar un vínculo de solidaridad y aprecio, establecer un contexto que facilite la colaboración entre los interlocutores (Haverkate, 1994: 99). Por ello, se suele considerar una estrategia de afiliación tanto de la imagen del destinatario como de la del emisor. Pero también puede ser interpretado como un acto de amenaza de la imagen social de éste. 
tro de su argumento y otras, la mayoría, como simple excusa para abordar cualquier asunto más o menos relacionado sobre el que deciden expresarse.

\subsection{Las referencias a la noticia y a sus protagonistas. (Des)cortesía hacia el medio} (periódico La Vanguardia) y su público

Ser lector habitual de un determinado periódico es formar parte de algún modo de una comunidad imaginaria, de un grupo invisible de personas que tienen algo en común. Es frecuente que los lectores de los distintos periódicos se consideren a sí mismos como "invitados" a un evento especialmente creado para ellos y en el que han participado o influido de algún modo. Su imagen de afiliación suele prevalecer contra toda crítica negativa, y no es muy habitual que los lectores se quejen metadiscursivamente de su periódico (del público, colectivo del cual forman parte) en los foros. Pero hay formas típicas de hacerlo, indirectas, que, desviando la atención hacia juicios o referentes completamente ajenos a lo propuesto, consiguen desautorizar o ridiculizar al medio o al colectivo que participa en el foro. Lo hace "xavi" aludiendo irónicamente al exceso de atención que se le concede al encuentro entre el futbolista y el entrenador:

(5) xavi | 21/02/2008, 16:56 | |

hombre no creo q sea para tanto, quizás anuncian su próxima boda... [...];

lo hace "manel" redundando, por el mismo motivo, en el tópico:

(6) manel | 21/02/2008, 17:10 | |

Viva la ejpaña de charanga y pandereta[;]

lo hace "taxi driver" evidenciando (si lo interpretamos bien) la inconveniencia de que el periódico siga el juego a Raúl y contribuya a presionar a Aragonés:

(7) taxi driver $|21 / 02 / 2008,20: 34|$ cat $\mid$

Que manera más vil de influenciar al seleccionador. [...];

y lo hace "Inesperado" concluyendo que quienes se interesan por cosas de tan poco fuste en plena crisis (o sea, todos los periódicos y periodistas que han transmitido la noticia, así como todos los que están participando en el foro con sus opiniones) se comportan como "locos":

(8) INESPERADO | 21/02/2008, 19:31 | Barcelona | España

Está el patio como para hablar de Raúl y del seleccionador, el abuelo Aragones. Estamos enfrentando unas elecciones de las más complicadas desde la denominada transición. Estamos en una crisis económica que al parecer no ha llegado a nuestros políticos que viven en Babia.(Perdón leoneses: Babia en si es una maravilla). Estamos ante unas posibles secesiones en España similares a Serbia con los Kosovares. ¿Y nos preocupan Raúl y Aragones.? PAÍS DE LOCOS. 
No cabe duda, por otro lado, de que, como parte de esa comunidad lectora de La Vanguardia, la mayoría de los miembros actúan presuponiendo una determinada adscripción ideológica tanto para el periódico como para el resto de los lectores.

En el caso de La Vanguardia, que es una cabecera catalana, la mayoría de los lectores se consideran "progresistas", son catalanes y seguidores del Barça (rivales, por tanto, de todo lo que se relaciona con el Real Madrid). Quienes no se consideran "progresistas" o/ni "catalanes" o/ni "seguidores del Barça" difícilmente podrán evitar, si participan activamente en el foro, verse implicados en el juego de opinar sobre alguno de esos tres temas "crónicos" en la relación España-Cataluña, o soslayarlos: a) el independentismo de Cataluña y la "defensa" del catalán (en su enfrentamiento con España y el español); b) la dudosa representatividad y capacidad de la selección "española" de fútbol (la roja), y $c$ ) cierta saña contra el (odiado) Real Madrid, considerado tradicionalmente el equipo favorecido por los sucesivos gobiernos, y contra sus jugadores (en este caso, centrada en Raúl).

De hecho, son muy escasas las intervenciones en las que se habla solamente de fútbol y se centran exclusivamente en alguno de los puntos de vista propuestos en la noticia: a) Raúl y la defensa de su imagen de afiliación como jugador (no conflictivo) de la selección española:

(9) xavi | 21/02/2008, 16:56 | |

[...] en todo caso tendría q ir convocado pq está en forma e indiscutiblemente es uno de los mejores delanteros de España[;]

(10) Maria | 21/02/2008, 20:48 | Lerida | Catalonia

Raul se ha de quedar en casa, si juega la figura no España no llega ni a cuartos, esta acabadooooo, corre mucho y no pilla nada

(11) da risa | 21/02/2008, 21:35 | |

Raul está pasado de moda, que se quede en casa y listo.

(12) retiro $|21 / 02 / 2008,22: 16| \mid$

Raul esta caduco para la seleccion. La seleccion es cosa de jovenes y no de viejos.

b) Luis Aragonés y la defensa de su imagen de autonomía (que tiene más apoyos que Raúl):

(13) taxi driver | 21/02/2008, 20:34 | cat

Que manera más vil de influenciar al seleccionador. Esto huele a chamusquina, debe ser que Raul no quiere perderse las primas de la Eurocopa. Que vayan los que se han ganado el derecho a ir y no los enchufados, aunque sea a calentar banquillo, mejor se queda en casa que ya huele a capitan rancio.

(14) | Julio | 21/02/2008, 20:19 | |

Esto huele a bajada de pantalones. 
(15) Yamandú | 22/02/2008, 02:02 | masquefa 08783 | espanta

Yo no se cuando se van a dar cuenta de que a Luis no le gusta que le exijan "que Raul si, que Raul no", dejenlo en paz al entrenador. No le digan que debe hacer y verán como lo cita, pero no va a aceptar de citarlo porq otro se lo diga, entendeis?

(16) Voltio | 21/02/2008, 19:39 | |

Si fue a petición del futbolista es que .... 1.- Estaban realmente enfrentados, 2.- Fue Raúl quien ofendió a Luis.... Desde luego, si ese va a la Eurocopa es que el Seleccionador se los ha bajado hasta los tobillos.... .iiii

(17) Francisco Franco | 22/02/2008, 11:03 | |

Raúl perdonó a Aragonés, ? en España las gallinas cagan para abajo? El único país. De los contrario le monta otra manifestación de fascistoides huliganer

En nuestro corpus, las intervenciones que surgen a partir de la noticia, son, como decíamos, ciertamente escasas. Y, desde el punto de vista lingüístico, resultan las contribuciones menos descorteses (o, si se quiere, más "neutras"). Se expresan en tercera persona y enlazan con los contenidos (digamos) "objetivos" del periódico.

Lo más habitual, sin embargo, es que la opinión de los lectores llegue ya (previamente) orientada desde el punto de vista ideológico o crítico (incluso en estas intervenciones, que pasan fácilmente de la tercera persona a la segunda) o que asuman sobre los protagonistas de la noticia creencias ("verdades") que no están, en rigor, en el escrito noticioso, y que reflejan un conocimiento "enciclopédico" y muchas veces "prejuicioso" de lo que se trata. Una forma clara de marcar explícitamente la rivalidad, potenciando simultáneamente su imagen de autonomía (respecto de los que no piensan igual) y la de afiliación (con el grupo de sus iguales).

El alineamiento es visible desde la primera intervención, a las 16.36 horas:

(18) da risa | 21/02/2008, 16:36 | |

el Madrid es y sera el equipo de los franquistas. Tiene fondos inagotables por ese conducto;

y se hace patente luego, con indudable intención, no solo en las opiniones, sino incluso en los propios datos ${ }^{9}$ que proporcionan los distintos opinantes. Así, tras ese primer impulso de "da risa", responde "Paquito", que se localiza en "Lleida | España":

9 En la cabecera de cada opinión pueden figurar hasta 5 datos: nickname, fecha, hora, localidad y país: Paquito | 21/02/2008, 17:13 | Lleida | España. De ellas, fecha y hora los pone automáticamente la herramienta, es obligatorio el primero y los dos últimos son opcionales. Es significativa la localización que hacen de sí mismos los lectores: para algunos, el lugar de Cataluña en que se encuentran es "España"; para otros, "Catalunya" o "Catalonia", o simplemente "cat" ("Caput Castellae" -representativo nickname, por cierto-, de Madrid, escribe en la casilla "país": "El de Mortadelo y Filemón"). 
(19) Paquito | 21/02/2008, 17:13 | Lleida | España

¿De los franquistas? Ahora es el equipo de la integración española, es una multinacional bien gestionada y un emblema nacional, com el BS, el BBVA, Telefónica, etc, mientras que el barça mi ex-equipo se ha provincializado, obligando a los cracks a tomar clases de catalán en vez de ponerlos a jugar, ...

Pero observemos cómo, casi imperceptiblemente, hemos pasado de "da risa" a "Paquito", que toma como referencia no ya los contenidos del escrito periodístico, sino lo dicho por "da risa", para centrar su discrepancia (que es también acuerdo -afiliación- con otros muchos). Y así llegamos al aspecto de ciber(des)cortesía que más nos interesa aquí: el que surge en los opinantes que se pronuncian explícitamente sobre lo dicho, insinuado o propuesto antes por otro u otros opinantes del foro.

\subsection{1. (Des)cortesía con otros participantes en el foro}

Ya hemos visto cómo, en el caso de la conferencia de prensa conjunta de Raúl González y Luis Aragonés, aunque lo más importante era la posible trascendencia pública de sus respectivas imágenes de afiliación y autonomía, ambos ponían en juego además su propia imagen personal (face, con su historia incluida) el uno para con el otro y los dos para con los demás, de ahí todas las precauciones con que se expresaban.

Los opinantes en el foro de opinión están, en cambio, participando de una comunicación mediada por la tecnología. No se encuentran in praesentia; son, de hecho, "anónimos" (para participar no precisan identificarse personalmente más allá del nickname o "nombre clave", que pueden inventar libremente cada vez); pueden intervenir (unilateralmente) tantas veces como deseen; su opinión puede versar sobre cualquier cosa (más o menos relacionada con la noticia) y ni siquiera cuenta más allá del propio foro (espacio y tiempo) en que aparece; más aún: aunque obtengan reatroalimentación de otros participantes en el foro, no tienen por qué tenerla en cuenta ni sentirse obligados a responder (en realidad, no tienen ni por qué leerla). Todo esto propicia un modo de comunicación muy particular, que ayuda a explicar muchos de sus rasgos de (des)cortesía (y, por añadidura, de lenguaje) más destacados, pues significa-obsérvese-que quienes escriben en el foro, en rigor, no están implicados personalmente ni en lo dicho ni en la autoría de lo dicho; no necesitan, pues, "construirse" como sujetos; no precisan tener en cuenta a sus receptores ni, en consecuencia, actualizar su relación con ellos en un determinado tono formal/informal (que influya luego en el intercambio). Sus autores pueden contar, en resumen, con la impunidad social de sus actos comunicativos.

Vinculados por este contrato de interacción previo, implícito, y actuando en tal contexto, parece claro que 
a) los participantes en estos foros de opinión no ponen en juego su propia imagen (face) ni esta se ve afectada por lo dicho, y que, por lo tanto,

b) la cortesía "interaccional" (respecto de su imagen y la de sus interlocutores) no precisa expresión explícita en sus textos;

c) por el contrario, el simple hecho de participar en el foro ubica ideológica y vivencialmente a los participantes de forma concreta junto o frente a lo demás y los demás; por eso, las relaciones de afiliación/autonomía se manifiestan e importan mucho más que las estrategias de imagen (face), que -como hemos dicho- no suelen ponerse en juego.

Si echamos un vistazo a todas las intervenciones recogidas en el anexo, comprobaremos que ni una sola contiene saludo alguno, ni despedida explícita, ni alabanza o halago hacia otra persona particular, ni precauciones oratorias, ni atenuadores léxicos; ni siquiera es muy frecuente la expresión explícita de "acuerdo" con otras opiniones anteriores. Todos los opinantes van directamente al grano, y en un tono que podríamos calificar de "bastante rotundo"; excepto uno (que utiliza además el usted para el plural, por lo que no es descartable que sea rasgo dialectal), todos tutean a los demás; pocos se limitan a expresar simplemente una opinión, casi siempre se quejan de algo o refutan a alguien.

Pero el hecho de que, en tales circunstancias, discrepar con otros participantes ( $\tan$ anónimos como uno/a mismo/a) no sea -no puede serlo- descortesía y en general la cortesía explícita no se sienta como necesaria (puesto que no hay relación interpersonal y la propia imagen no se pone en juego) no es óbice para que la expresión del acuerdo (afiliación) y la discrepancia (autonomía, autonomíaafiliación) alcancen diferentes grados de implicación personal y (des)cortesía. Así, como veremos, aunque no sea fácil encontrar atenuadores léxicos explícitos, por ejemplo, sí podemos encontrar diversas estrategias persuasivas (e indirectas) de atenuación de la discrepancia; aunque no suele expresarse explícitamente el acuerdo, sí podemos encontrar manifestaciones de acuerdo indirectas, expresadas mediante alo-repeticiones y argumentaciones paralelas...

Lógicamente, la (des)cortesía surge cuando en nuestro discurso se implica (directa o indirectamente) a un tú. Si el/la opinante expresa simplemente su opinión sobre lo aparecido en el periódico, sea positiva o negativa, de acuerdo o de discrepancia (incluso si lo hace con cierto énfasis, con ironía o apasionadamente), ningún otro participante en el foro tiene por qué darse por aludido (más allá de adherirse ideológicamente o no a lo dicho). Así ocurre, por ejemplo, en la intervención de Jaume:

(20) JAUME | 21/02/2008, 8:48 | |

Yo me pregunto, si Raúl fuera un jugador del Barça, los medios informativos deportivos ¿le darían tanta importancia sino fuera convocado a la Selección española? 
Podemos reconocer a "Jaume" como seguidor del Barça y percibir que con lo que dice se afilia con quienes como él viven la rivalidad con el Real Madrid y sienten como favoritismo el trato que la sociedad, el seleccionador y los medios dan a este equipo y a sus jugadores. Pero nada más. Esta afiliación (o autonomía, que para el caso valdría lo mismo) es, ya lo decíamos, consustancial al simple hecho de intervenir activamente en el foro. Tanto si opinamos lo mismo que Jaume como si opinamos cualquier otra cosa, no hay (des)cortesía hacia nadie (del foro) en su mensaje. Enseguida, sin embargo, otro opinante, aun hablando en tercera persona, se refiere tan claramente a lo dicho por Jaume, que lo implica inequívocamente (lo instaura) como un tú, y eso convierte a su mensaje en susceptible de ser interpretado en términos de (des)cortesía para con él, además de afiliación/autonomía, naturalmente:

(21) INESPERADO | 21/02/2008, 19:31 | Barcelona | España

Está el patio como para hablar de Raúl y del seleccionador, el abuelo Aragones. Estamos enfrentando unas elecciones de las más complicadas desde la denominada transición. Estamos en una crisis económica que al parecer no ha llegado a nuestros políticos que viven en Babia.(Perdón leoneses: Babia en si es una maravilla). Estamos ante unas posibles secesiones en España similares a Serbia con los Kosovares. ¿Y nos preocupan Raúl y Aragones.? PAÍS DE LOCOS.

Inesperado parece incluir a Jaume, por lo dicho respecto al jugador Raúl, en el plural de locos de este país que, ¡con la que está cayendo...!, se preocupan por cosas absolutamente triviales. Ciertamente, esto podemos interpretarlo como una agresión contra la imagen positiva de Jaume (y todos los que sienten/hacen como él), además de una expresión de discrepancia-autonomía por parte de Inesperado. La descortesía puede ser clara, pero el anonimato y la previsible impunidad en que quedará la supuesta agresión le restan importancia y la convierten en intrascendente: los participantes no están poniendo realmente en juego su imagen ni esta va a verse realmente afectada por lo dicho o leído (Jaume, por cierto, nunca vuelve a intervenir luego).

Si además de expresar simple discrepancia se manifiesta contrariedad, disgusto, irritación, enfado, ira..., rivalidad o enemistad hacia el otro, la descortesía se hace patente y se debe considerar deliberada. Puesto que la imagen personal no está realmente en juego, todas estas manifestaciones suelen estar motivadas por la ideología y/o el alineamiento político o deportivo.

Naturalmente, en las manifestaciones del foro no todo son discrepancias (también hay afiliación), pero tampoco abundan las manifestaciones corteses, casi ausentes por completo. A continuación veremos algunas de las principales estrategias ${ }^{10}$ de discrepancia, afiliación y (des)cortesía que podemos encon-

10 Véanse las clasificaciones sobre las estrategias de (des)cortesía propuestas por Culpeper (1996) y Alba-Juez (2008). 
trar en el foro, así como los recursos lingüísticos mediante los que se manifiestan.

\subsubsection{Discrepancia explícita con descortesía}

Algunos opinantes expresan explícitamente, sin disimulo, su desacuerdo con otros participantes en el foro; y no solo esto, sino que se muestran al mismo tiempo descorteses mediante la utilización de insultos, descalificaciones o valoraciones negativas.

En 22, por ejemplo, se recurre al insulto directo, en respuesta a la intervención que ya conocemos de Inesperado (21):

(22) Al-Caxera 21/92/2008 Toledo España

Inesperado, ¿de dónde sacas tú que España está ante posibles secesiones como la de Serbia-Kosovo? Estamos hasta la coronilla de agoreros que estáis continuamente fastidiándonos la vida. ¿Cómo es posible que cuando se habla de algo tan poco trascendente como es el tema Aragonés se te ocurra a ti compararnos con los Balcanes. Tú no estás loco, creo, tu en vez de hablar berreas.

Como vemos, el insulto se formula además de manera enfática: la ironía inicial (tú no estás loco), que ya constituye por sí sola una valoración negativa (sobre todo teniendo en cuenta que Inesperado hablaba de "país de locos"), se ve reforzada por la metáfora posterior (tú en vez de hablar berreas). Se recurre además al pronombre personal tónico, que aparece de forma reiterada (tú... tú) con valor enfático-contrastivo, muy valioso para marcar distancias en las respectivas posiciones.

En general, el tono de la intervención 22 (que muestra tanto el desacuerdo como el enfado) es descortés desde la interrogación inicial, que no es sino una pregunta orientada (retórica) que podemos interpretar como un reproche por comparar una situación trivial (la polémica entre Luis Aragonés y Raúl González) con un problema político realmente serio (el conflicto en los Balcanes). Reproche que se reitera posteriormente mediante la formulación de otro enunciado interrogativo (¿Cómo es posible que cuando se habla de algo tan poco trascendente como es el tema Aragonés se te ocurra a ti compararnos con los Balcanes?).

Además, aparece ya desde el principio una descalificación, aunque formulada de una manera generalizada: "estamos hasta la coronilla de agoreros que estáis fastidiándonos la vida". Resulta interesante el contraste entre el nosotrosvosotros. El plural inclusivo, que muestra que el interlocutor se hace eco de una opinión generalizada, le permite al mismo tiempo justificar de alguna forma la propia descalificación (o quizá diluir su intensidad) que va a realizar a otro participante en el foro. No se trata de una estrategia para minimizar, atenuar la descortesía deliberada hacia el participante llamado "Inesperado", pero 
sí de una fórmula mediante la que "Al-Caxera" busca resguardar o proteger su propia imagen (actividad de autoimagen) frente a otros participantes. No olvidemos que un insulto -o descalificación- puede desacreditar no solo a la persona a la que va dirigido, sino también a quien lo realiza. De ahí ese especial interés por evitar esto, algo que llega a convertirse en una tendencia generalizada, al menos en este foro. De ninguna manera puede amenazarse la adhesión con aquellos con los que existe cierta afinidad (bien ideológica o bien surgida a partir de un hecho coyuntural: el fútbol, en el ejemplo propuesto). La descalificación de Inesperado está intensificada además por un procedimiento argumental indirecto: el paralelismo analógico. Quienes se ocupan de frivolidades estando "como está el patio" están locos, dice Inesperado; quien, como Inesperado, da el paso de lo intrascendente (fútbol) a la tragedia (posibles secesiones en España que nos llevarían a una guerra), no (solo) está loco, sino que berrea (es decir, no habla, no razona, es un fanático).

En 23 se intensifica también la descalificación:

(23) Vergüenzaajena 21/02/2008

Vas de listo, pero lo que eres es un listillo. Todos (menos tú) saben que el equipo de Luis, y de toda su familia, es el madrit, aunque luego le tocó jugar en el Atleta. ¿No lo sabías? Pues TOMA NOTA. ¿O es que crees que el equipo de Zubi es el Barça? NO: es y siempre será el Athletic. Pero son profesionales, no lo olvidemos. Raúl no debió jugar cuando estuvo pasando aquel bache, y fue porque los periodistas de la capital son unos arrogantes y machacones. Y ahora lo está purgando

Si Vas de listo puede resultar un comentario negativo (se "va de" lo que no se es), ser un listillo, con el diminutivo peyorativo y presentado como oposición mediante la adversativa ("pero..."), se aproxima ya a la ofensa (te has pasado de "listo", de puro tonto). La descortesía queda patente en el intento de ridiculizar o desacreditar al otro al acusarle de desconocer algo que la mayoría ya conoce mediante un argumento basado en el principio de gregarismo: todos (menos tú) saben que... Y también, a modo de reproche, se recurre a un enunciado interrogativo ( $¿$ No lo sabias?) seguido de una respuesta enfatizada (Pues TOMA NOTA), transcrita en versales (convención utilizada en la transcripción del discurso oral y en las reglas de netiqueta para destacar una palabra o sílaba reflejando acento de insistencia o volumen alto).

En 24 se utiliza de nuevo el diminutivo peyorativo (enteradillos) a modo de descalificación.

(24) jsorel 21/02/2008, 22:40

Para los enteradillos como "da risa" o "retiro". Atención, pregunta: ¿Cuál e el equipo de Luis de toda la vida? ¿Tendrá eso algo que ver con que no quiera saber nada de Raúl?

Por otra parte, en este ejemplo, la afiliación con el resto de los participantes en el foro se busca intentando resultar elocuente. Para ello, se juega con la in- 
tertextualidad apelando mediante interrogaciones retóricas u orientadas anunciadas con una fórmula propia del que fuera un famoso concurso de televisión española: "Atención: pregunta". Resultar afiliativo con los demás resulta particularmente importante cuando se trata de un acto de comunicación público (no privado) y colectivo (por suma de individualidades), además de anónimo, pues el simple hecho de participar en él, ya lo hemos dicho, ubica ideológica $\mathrm{y}$ vivencialmente a los participantes.

A diferencia de lo que hemos visto en los ejemplos 22, 23 y 24, no es habitual que se recurra al insulto o a la descalificación, incluso cuando la situación se prestaría a ello, ya que estos suelen merecer cierta sanción social. Y, además, si algo se limita en los foros de opinión (mediante sus filtros) es precisamente el insulto directo. Por el contrario, son frecuentes las intervenciones en las que el participante muestra su desacuerdo con la opinión de otro/s y defiende con cierta vehemencia, que puede resultar deliberadamente descortés, la suya propia:

(25) "Fins el gorro de la roja" ||21/02/2008, 17:41

Paquito, seguns un estudi de la universitat de Navarra el teu exequip, tant provincià, és el club més mediatic del món y té per darrere Manchester United, Milán, Chelsea y Real Madrid. Ara calla una estoneta.

(26) Paquito | 21/02/2008, 17:55

Ah y no me pienso callar, esto es para hablar, ¿no? Visca la plataforma "Tots units fem força" Visca la roja

El participante cuyo nikname es "Fins el gorro de la roja" pide a "Paquito" que se calle (Ara calla una estoneta). Y además lo hace mediante un imperativo y sin ningún minimizador de la fuerza ilocutiva impositiva de la petición directa. No obstante, realiza esta petición tras un razonamiento en el que ha recurrido a un argumento de autoridad (seguns un estudi de...). Mediante esta estrategia no solo justifica su propia opinión, sino que consigue también desautorizar al otro.

En el foro de opinión que analizamos se suelen justificar las opiniones mediante este tipo de argumentos u otros similares (analogías, comparaciones). Sin duda, una opinión bien razonada -no gratuita, con criterios suficientes para ser bien considerada o aceptada por los demás- realza la imagen de autonomía del participante que la realiza y puede contribuir también a que su imagen de afiliación no se vea dañada en situaciones en las que, como en la expuesta, amenaza -mediante una petición impositiva- la imagen de autonomía y de afiliación de otro participante.

Por su parte, Paquito, el participante afectado, realza en su respuesta (Ah y no me pienso callar, esto es para hablar, ¿no?) su imagen de autonomía al rei- 
vindicar su derecho a expresarse libremente, algo que está en la base de las normas implícitas asumidas por los participantes en un foro de opinión. Reacciona, sin duda, ante la negativa a que participe, de la forma requerida, en el intercambio en el que se halla inmerso, lo que supone la violación deliberada del principio de cooperación (Grice 1991: 516). Lanzar sus consignas en catalán (no en castellano) contribuye a realzar su imagen de autonomía, lo cual le permite reforzar con contundencia su posición ideológica ("a pesar de ser catalán, defiendo a la selección española") ante un hecho puntual y, presumiblemente, ante cuestiones políticas de más amplio alcance.

La simple desautorización de la opinión del otro puede resultar también una fórmula implícita de descalificación, tan descortés como si se realizara de manera directa o incluso se insultara.

\subsubsection{Discrepancia sin descortesía}

Para mostrar el descuerdo hay una estrategia discursiva no descortés, que podríamos calificar de neutra, presente también en la lengua hablada, especialmente interesante: la alo-repetición o heterorrepetición, es decir, la repetición total o parcial de las palabras del otro.

(27) Da risal 21/02/2008, 16:36

El Madrid es y sera el equipo de los franquistas. Tiene fondos inagotables por ese conducto.

(28) Paquito| 21/02/2008, 17:13|Lleida|España

¿De los franquistas? Ahora es el equipo de la integración española, es una multinacional bien gestionada y un emblema nacional, como el BS, el BBVA, Telefónica, etc, mientras que el barça mi exequipo se ha provincializado, obligando a los cracks a tomar clases de catalán en vez de ponerlos a jugar,...

(29) manel | 21/02/2008, 17:28 ||

Paquito, su tu idea de integración son BBVA o Telefónica, dos empresas tan bien bien gestionadas que llevan decenios vampirizando los bolsillos de los ciudadanos, pues me alegro que el Barça sea tu ex equipo.

(30) Paquito | 21/02/2008, 17:54 ||

Más mediático sí, lo que normalmente pasa en ese club es de "gran hermano".

En el ejemplo 28, el participante "Paquito" manifiesta a través de una interrogativa-eco (¿de los franquistas?) su extrañeza o su sorpresa ante las palabras de "Da risa", como preludio de su desacuerdo. Y en 29 sucede lo mismo, se repite el tema discursivo y éste introduce los argumentos a partir de los que "manel" muestra la disconformidad con lo expuesto previamente. En ambos casos surge la discrepancia, pero la presencia de la heterorrepetición, aun cuando puede tener cierto sentido irónico incluso, no permite interpretarla, en rigor, como des- 
cortesía. No es inusual discrepar de una forma elocuente, incluso con humor, lo que sin duda potencia un efecto social afiliativo con los demás.

Las repeticiones ${ }^{11}$ resultan muy frecuentes -e incluso necesarias- en los foros de opinión por su papel como recursos de cohesión textual. No olvidemos que, como mecanismo al servicio de la progresión temática, la repetición permite relacionar intervenciones que no son sucesivas (bien al contrario, entre ellas puede haber transcurrido mucho tiempo). Pero la repetición no solo permite retomar el tema de alguna intervención previa, sino también mostrar el acuerdo o desacuerdo con lo expuesto, añadir matices, digresiones, ironizar... (v. Vigara, 1995).

\subsubsection{Afiliación}

Las repeticiones constituyen, por otra parte, interesantes estrategias para intentar ratificar el acuerdo con el punto de vista del otro. La búsqueda de un efecto afiliativo parece clara en ejemplos como estos:

(31) Voltio | 21/02/2008, 19:39 ||

Si fue a petición del futbolista es que ... 1.Estaban realmente enfrentados, 2.Fue Raúl quien ofendió a Luis... Desde luego, si ese va a Europa es que el Seleccionador se los ha bajado hasta los tobillos...........iiiii

(32) Julio | 21/02/2008, 20:19 ||

Esto huele a bajada de pantalones.

(33) Taxi driver | 21/02/2008, 20:34 ||

Que manera más vil de influenciar al seleccionador. Esto huele a chamusquina, deber ser que Raul no quiere perderse las primas de la Eurocopa. Que vayan los que se han ganado el derecho a ir y no los enchufados, aunque sea a calentar banquillo, mejor se queda en casa que ya huele a capitán rancio.

(34) Da risa | 21/02/2008, 21:35 ||

Raúl está pasado de moda, que se quede en casa y listo.

(35) retiro | 21/02/2008, 22:16 | |

Raul está caduco para la selección. La selección es cosa de jóvenes y no de viejos.

En estos casos se busca intencionalmente la empatía con el otro, con aquel con el que existe afinidad ideológica o sobre un acontecimiento determinado. Y bien solo se repiten sus palabras -de forma total o parcial- o bien la repetición contribuye una vez más al desarrollo del tema discursivo. Como señala Camacho Adarve, las reformulaciones parafrásticas colaboran en el desarrollo del tema, "realizando generalizaciones, particularizaciones, concreciones, enu-

11 Bernal analiza las diferentes funciones de (des)cortesía de las alo-repeticiones en la conversación coloquial (2006). 
meraciones, contradicciones, contrastes, intensificaciones o relieves persuasivos" (2009: 38).

Precisamente lo más frecuente es que la repetición sirva para el desarrollo de una opinión, que, aunque corrobore lo apuntado por otro participante, contribuya de alguna manera a introducir un nuevo argumento. Estrategia esta que permite, en última instancia, reivindicar también la imagen de autonomía del que opina.

\section{A modo de conclusión}

Como hemos visto en el ejemplo, en los foros ("bancos de opinión") de los periódicos digitales, los opinantes se mantienen activos simultáneamente con la cabecera, con el público (del que forman, a su vez, parte) y con el resto de los lectores del foro, de los cuales pueden recibir réplica o retroalimentación. El simple hecho de participar en el foro los convierte en protagonistas activos de cada una de esas tres instancias de enunciación, en las que, salvo que expresen explícitamente algún género de discrepancia, están afiliados con todos los demás miembros del grupo. Como la comunicación, mediada, es diferida y anónima, los participantes no ponen en juego su imagen personal (frente a lo que ocurría en la rueda de prensa entre Raúl y Luis Aragonés), así que, en general, la cortesía interaccional no precisa ser expresada explícitamente y la mayor parte de los actos de (des)cortesía que surgen giran en torno a la expresión del acuerdo (afiliación) y la discrepancia (autonomía, autonomía-afiliación), en la que se muestran diferentes grados de implicación personal y del destinatario.

\section{Referencias bibliográficas}

Alba-Juez, L. (2007): "On the impoliteness of some politeness strategies: a study and comparison of the use of some pragmatic markers of impoliteness in British English and American English, Peninsular Spanish and Argentine Spanish". En Garcés-Conejos, P., M. Padilla, R. Gómez y L. Fernández (eds.): Studies in Intercultural, Cognitive and Social Pragmatics. Newcastle, Cambridge Scholars Publishing, págs. 37-56.

Alba-Juez, L. (2008): "Sobre algunas estrategias y marcadores de descortesía en español peninsular y argentino: ¿Son españoles y argentinos igualmente descorteses?”. En Briz, A., A. Hidalgo, M. Albelda, J. Contreras y N. Hernández (eds.): Cortesía y conversación: de lo escrito a lo oral. III Coloquio Internacional del Programa EDICE. Valencia, Departamento de Filología Española de la Facultad de Filologia, Traducció i Comunicació de la Universitat de València y el Programa EDICE, págs. 80-97.

Bernal Linnersand, M. (2006): "La alo-repetición como estrategia de cortesía y de descortesía en la conversación". En J. Murillo (ed.): Actos de habla y cortesía en distintas variedades del español. Perspectivas teóricas y metodológicas. II Coloquio 
Internacional del Programa EDICE. Costa Rica, Universidad de Costa Rica y Programa EDICE, págs. 55-79.

Bravo, D. (1999): “¿Imagen positiva vs imagen negativa? Pragmática socio-cultural y componentes de face", Oralia, 2, págs. 155-184.

Camacho Adarve, M. ${ }^{a}$ M. (2009): Análisis del discurso y repetición: Palabras, actitudes y sentimientos, Anejos Oralia, 5, Madrid, Arco/Libros.

Charaudeau, P. (2000): "La problemática de base de una lingüística del discurso". En Bustos Tovar, J.J. de, P. Charaudeau, J. L. Girón Alconchel, S. Iglesias Recuero, y C. López Alonso (eds.): Lengua, discurso, texto. I Simposio Internacional de Análisis del Discurso. Madrid, Visor, págs. 39-52.

Culpeper, J. (1996): “Towards an anatomy of impoliteness", Journal of Pragmatics, 25, págs. 349-367.

Grice, H.P. (1991): "Lógica y conversación”. En Valdés Villanueva, L. (ed.): La búsqueda del significado. Lecturas de filosofía del lenguaje. Murcia, Tecnos, págs. 511-530.

Haverkate, H. (1994): La cortesía verbal. Estudio pragmalingüistico. Madrid, Gredos.

Hernández Flores, N. (2006): "Cortesía y oscilación de la imagen social en un debate televisivo". En Murillo, J.: Actos de habla y cortesía en distintas variedades del español. Perspectivas teóricas y metodológicas. II Coloquio Internacional del Programa EDICE. Costa Rica, Universidad de Costa Rica y Programa EDICE, págs. 37-53.

Kerbrat-Orecchioni, C. (2001): Les actes de langage dans le discours. Paris, Armand Colin.

Kress, G. (2005): El alfabetismo en la era de los nuevos medios de comunicación. Granada-Málaga, Aljibe.

Vigara Tauste, A. M. ${ }^{a}$ (1995): "Comodidad y recurrencia en la organización del discurso coloquial”. En Cortés Rodríguez, L. (ed.): Actas del I Simposio sobre análisis del discurso oral. Almería, Universidad de Almería, págs. 173-208.

Vigara Tauste, A. M. ${ }^{a}$. (2004): "Comunicación y lenguaje juveniles a través de las TIC (Tecnologías de la Información y la Comunicación). Análisis lingüístico de los materiales". En Comunicación y lenguaje juveniles a través de las TIC, págs. 42-65. Injuve, edic. electrónica, http://www.injuve.mtas.es/injuve/contenidos.item.action?i Yus, F. (2010): Ciberpragmática 2.0. Nuevos retos del lenguaje en internet. Barcelona, Ariel.

\section{Anexo 1}

\begin{tabular}{c|c|l}
\hline & Lector/ Hora /Lugar & \multicolumn{1}{c}{ Texto } \\
\hline 1 & da risa | 21/02/2008, 16:36 | | & $\begin{array}{l}\text { El Madrid es y sera el equipo de los franquistas. } \\
\text { Tiene fondos inagotables por ese conducto. }\end{array}$ \\
\hline 2 & Sabih | 21/02/2008, 16:56 | | & $\begin{array}{l}\text { Hombre no creo q sea para tanto, quizás anuncian su } \\
\text { próxima boda... en todo caso tendría q ir convocado } \\
\text { pq está en forma e indiscutiblemente es uno de los } \\
\text { mejores delanteros de españa }\end{array}$ \\
\hline 3 & manel | 21/02/2008, 17:10 | | & Viva la ejpaña de charanga y pandereta! \\
\hline
\end{tabular}




\begin{tabular}{|c|c|c|}
\hline & Lector/ Hora /Lugar & Texto \\
\hline 4 & $\begin{array}{l}\text { Paquito | 21/02/2008, } \\
17: 13 \text { | Lleida | España }\end{array}$ & $\begin{array}{l}\text { ¿De los franquistas? Ahora es el equipo de la } \\
\text { integración española, es una multinacional bien } \\
\text { gestionada y un emblema nacional, com el BS, el } \\
\text { BBVA, Telefónica, etc, mientras que el barça mi } \\
\text { ex-equipo se ha provincializado, obligando a los cracks } \\
\text { a tomar clases de catalán en vez de ponerlos a jugar, .... }\end{array}$ \\
\hline 5 & Oli | 21/02/2008, 17:25 | | & $\begin{array}{l}\text { Que hagan un partido amistoso entre Espana y Servia, } \\
\text { en Xipre por ejemplo. }\end{array}$ \\
\hline 6 & manel | 21/02/2008, 17:28 | | & $\begin{array}{l}\text { Paquito, si tu idea de integración son BBVA o } \\
\text { Telefónica, dos empresas tan bien gestionadas que } \\
\text { llevan decenios vampirizando los bolsillos de los } \\
\text { ciudadanos, pues me alegro que el Barça sea tu } \\
\text { ex-equipo. }\end{array}$ \\
\hline 7 & J. | 21/02/2008, 17:30 | | & $\begin{array}{l}\text { Zi Raul é er capitán del equipo nasional, uséase, del } \\
\text { Madriz, entonce tiene que zer capitán de la roja. Viva } \\
\text { Ehpaña! }\end{array}$ \\
\hline 8 & $\begin{array}{l}\text { Fins el gorro de la "roja" } \\
|21 / 02 / 2008,17: 41| \mid\end{array}$ & $\begin{array}{l}\text { Paquito, segons un estudi de la universitat de Navarra } \\
\text { el teu ex-equip, tant provincià, és el club més mediatic } \\
\text { del món i té per darrere Manchester United, Milán, } \\
\text { Chelsea y Real Madrid. Ara calla una estoneta. }\end{array}$ \\
\hline 9 & $\begin{array}{c}\text { Raul } 4 \text { ever } \\
|21 / 02 / 2008,7: 44| \mid\end{array}$ & $\begin{array}{l}\text { Sres Manel y J, aprendan a hablar castellano escriban } \\
\text { en otras lenguas si así lo hacen mejor, pero yo no } \\
\text { conozco ningun idioma en que se escriba ni ejpaña } \\
\text { ni ehpaña... }\end{array}$ \\
\hline 10 & Paquito | 21/02/2008, 17:48 | | & $\begin{array}{l}\text { Visca la roja! Tots unit fem força... si del nord o del } \\
\text { sud...tenim un nom que sap tothom España, España, } \\
\text { España }\end{array}$ \\
\hline 11 & J. | 21/02/2008, 17:53 | | & $\begin{array}{l}\text { Pues yo si lo conozco, se le llama "castizo" y no és un } \\
\text { dialécto, es un idioma propio según el PP. }\end{array}$ \\
\hline 12 & Paquito | 21/02/2008, 7:54 | | & $\begin{array}{l}\text { Más mediático sí, lo que normalmente pasa en ese } \\
\text { club es de "gran hermano". }\end{array}$ \\
\hline 13 & Paquito | 21/02/2008, 17:55 | | & $\begin{array}{l}\text { Ah y no me pienso callar, esto es para hablar, ¿no? } \\
\text { Visca la plataforma "Tots units fem força" Visca la roja }\end{array}$ \\
\hline 14 & $\begin{array}{l}\text { prospero | 21/02/2008, } \\
\text { 18:05 | Rubí | España }\end{array}$ & $\begin{array}{l}\text { Que pesados con el tema de Raul éste jugador tuvo su } \\
\text { etapa y ahora lo que hay que hacer es respetar a los } \\
\text { jugadores que juegan en la selección,con él cómo } \\
\text { jugador nunca se gano nada en la selección,ya puestos } \\
\text { que reclamen a Butrageño. }\end{array}$ \\
\hline
\end{tabular}




\begin{tabular}{|c|c|c|}
\hline & Lector/ Hora/Lugar & Texto \\
\hline 15 & $\begin{array}{l}\text { Sensato | 21/02/2008, } \\
\text { 18:19 | | ESPAÑA }\end{array}$ & $\begin{array}{l}\text { El que defienda a Luis, no tiene mas argumento que } \\
\text { el de defender a todos los jugadores de España. } 1^{\circ} \text {. } \\
\text { El entrenador es quien tiene que poner a los jugadores } \\
\text { que mejor crea. } 2^{\circ} \text {. Los jugadores que ocupan el lugar } \\
\text { que ocupa Raul, tendrian que negarse a ir ya que se } \\
\text { les hace de menos al no reconocer que ellos tambien } \\
\text { juegan al futbol. Raul es bueno, pero nó } \\
\text { imprescindible }\end{array}$ \\
\hline 16 & nevat | 21/02/2008, 18:20 | | & $\begin{array}{l}\text { Que falta de respeto a la selección española y a los } \\
\text { aficionados. Eso es patriotismo, si señor. La Brunete } \\
\text { Mediática, los políticos, el presi de la Federación, } \\
\text { todos a meter cizaña con el dios Raulito. Para que } \\
\text { después, él se pasee en los mundiales y eurocopas, } \\
\text { creando conflictos en el vestuario y fallando penaltis } \\
\text { decisivos. Me imagino la que liarían si algún medio } \\
\text { del Barca o catalán montara una campañita similar, } \\
\text { con Valdes por ejemplo. Algunos sacarían los tanques } \\
\text { a la calle. }\end{array}$ \\
\hline 17 & Flora | 21/02/2008, 18:31 | | & $\begin{array}{l}\text { empieza la campaña y a politizar el futbol que se cre } \\
\text { raulito simbolo de que de la zorreria como } \\
\text { butragueño los poderosos de que amasar fortunas y } \\
\text { por eso les apoyan los derechistas }\end{array}$ \\
\hline 18 & JAUME | 21/02/2008, 8:48 | | & $\begin{array}{l}\text { Yo me pregunto, si Raúl fuera un jugador del Barça, } \\
\text { los medios informativos deportivos ¿le darían tanta } \\
\text { importancia sino fuera convocado a la Selección } \\
\text { española? }\end{array}$ \\
\hline 19 & PIPO | 21/02/2008, 19:29 | | & $\begin{array}{l}\text { Basta de abuelitos y jugadores forrados. Abrid las } \\
\text { puertas a los chavalitos (sub } 21 \text { etc) que seguro lo } \\
\text { hacen mejor. A los resultados me remito. }\end{array}$ \\
\hline 20 & $\begin{array}{c}\text { INESPERADO | 21/02/2008, } \\
\text { 19:31 | Barcelona | España }\end{array}$ & $\begin{array}{l}\text { Está el patio como para hablar de Raúl y del } \\
\text { seleccionador, el abuelo Aragones. Estamos } \\
\text { enfrentando unas elecciones de las más complicadas } \\
\text { desde la denominada transición. Estamos en una } \\
\text { crisis económica que al parecer no ha llegado a } \\
\text { nuestros políticos que viven en Babia.(Perdón leoneses: } \\
\text { Babia en si es una maravilla). Estamos ante unas } \\
\text { posibles secesiones en España similares a Serbia con } \\
\text { los Kosovares. ¿Y nos preocupan Raúl y Aragones.? } \\
\text { PAíS DE LOCOS. }\end{array}$ \\
\hline 21 & Voltio | 21/02/2008, 19:39 | | & $\begin{array}{l}\text { Si fue a petición del futbolista es que .... 1.- Estaban } \\
\text { realmente enfrentados, 2.- Fue Raúl quien ofendió a } \\
\text { Luis.... Desde luego, si ese va a la Eurocopa es que el } \\
\text { Seleccionador se los ha bajado hasta los tobillos.....iiii }\end{array}$ \\
\hline
\end{tabular}




\begin{tabular}{|c|c|c|}
\hline & Lector/ Hora /Lugar & Texto \\
\hline 22 & $\begin{array}{l}\text { Sotto voce | 21/02/2008, } \\
\text { 19:42 | Barcelona | España }\end{array}$ & $\begin{array}{l}\text { A JAUME: Si Raúl fuera del Barça no se le daría la } \\
\text { menor importancia. Primero -porque como dice } \\
\text { INESPERADO- bastantes problemas tenemos en } \\
\text { España para estas sandeces. Y después, porque el } \\
\text { Barça aporta excelentes jugadores y poco importa si se } \\
\text { sienten o no españoles. (Caso Oleguer). Raúl es para } \\
\text { el Real Madrid lo que Guardiola fue para el Barça: Un } \\
\text { símbolo.!! Lo que ahora hay por ahí, en todas partes, } \\
\text { en todos los equipos, son simples mercenarios }\end{array}$ \\
\hline 23 & $\begin{array}{c}\text { Bartleby | 21/02/2008, } \\
\text { 19:43 | La Roda }\end{array}$ & $\begin{array}{l}\text { Jaume, yo te contesto: lo mismo. Basta ya de } \\
\text { victimismo catalán }\end{array}$ \\
\hline 24 & | Julio | 21/02/2008, 20:19 | | & Esto huele a bajada de pantalones. \\
\hline 25 & $\begin{array}{l}\text { Taxi driver | 21/02/2008, } \\
\qquad 20: 34 \text { | cat | }\end{array}$ & $\begin{array}{l}\text { Que manera más vil de influenciar al seleccionador. } \\
\text { Esto huele a chamusquina, debe ser que Raul no } \\
\text { quiere perderse las primas de la Eurocopa. Que vayan } \\
\text { los que se han ganado el derecho a ir y no los } \\
\text { enchufados, aunque sea a calentar banquillo, mejor se } \\
\text { queda en casa que ya huele a capitan rancio. }\end{array}$ \\
\hline 26 & $\begin{array}{c}\text { Maria | 21/02/2008, } \\
\text { 20:48 | Lerida | Catalonia }\end{array}$ & $\begin{array}{l}\text { Raul se ha de quedar en casa, si juega la figura no } \\
\text { España no llega ni a cuartos, esta acabadooooo, } \\
\text { corre mucho y no pilla nada }\end{array}$ \\
\hline 27 & $\begin{array}{l}\text { Al-Caxera | 21/02/2008, } \\
\text { 20:50 | Toledo | España }\end{array}$ & $\begin{array}{l}\text { Inisperado, ¿de donde sacas tú que España está ante } \\
\text { posibles secesiones como la de Serbia-Kosovo? } \\
\text { Estamos hasta la coronilla de agoreros que estáis } \\
\text { continuamente fastidiándonos la vida. ¿Como es } \\
\text { posible que cuando se habla de algo tan poco } \\
\text { trascendente como es el tema Aragonés-Raúl se te } \\
\text { ocurra a ti compararnos con los Balcanes. Tu no estás } \\
\text { loco, creo, tu en vez de hablar berreas. }\end{array}$ \\
\hline 28 & da risa | 21/02/2008, 21:35 | | & $\begin{array}{l}\text { Raul está pasado de moda, que se quede en casa y } \\
\text { listo. }\end{array}$ \\
\hline 29 & retiro | 21/02/2008, 22:16 | | & $\begin{array}{l}\text { Raul esta caduco para la seleccion. La seleccion es } \\
\text { cosa de jovenes y no de viejos. }\end{array}$ \\
\hline 30 & tony | 21/02/2008, 22:19 | | & $\begin{array}{l}\text { Que pesados con el tema. Aburre más que le la } \\
\text { selección.cuando }\end{array}$ \\
\hline 31 & $\begin{array}{l}\text { chupoptero | 21/02/2008, } \\
\text { 22:33 | Barcelona | Catalunya }\end{array}$ & $\begin{array}{l}\text { Pues si el Raul está viejo para la selección, el aragonés } \\
\text { esta para que lo metan en un frasco de formol }\end{array}$ \\
\hline 32 & jsorel | 21/02/2008, 22:40 | | & $\begin{array}{l}\text { Para los enteradillos como "da risa" o "retiro". Atención, } \\
\text { pregunta: ¿Cuál e el equipo de Luis de toda la vida? } \\
\text { ¿Tendrá eso algo que ver con que no quiera saber } \\
\text { nada de Raúl? }\end{array}$ \\
\hline
\end{tabular}




\begin{tabular}{c|c|l}
\hline & Lector/ Hora /Lugar & \multicolumn{1}{c}{ Texto } \\
\hline 33 & $\begin{array}{c}\text { Vergüenzaajena | 21/02/2008, } \\
22: 49|\mathrm{BCN}|\end{array}$ & $\begin{array}{l}\text { jsorel: vas de listo, pero lo que eres es un listillo. } \\
\text { Todos (menos tú) saben que el equipo de Luis, y de } \\
\text { toda su familia, es el madrit, aunque luego le tocó } \\
\text { jugar en el Atleti. ¿No lo sabías? pues TOMA NOTA. } \\
\text { ¿O es que crees que el equipo de Zubi es el Barça? } \\
\text { NO: es y siempre será el Athletic. Pero son } \\
\text { profesionales, no lo olvidemos. Raúl no debió jugar } \\
\text { cuando estuvo pasando aquel bache, y fue porque los } \\
\text { periodistas de la capital son unos arrogantes y } \\
\text { machacones. Y ahora lo está purgando }\end{array}$ \\
\hline
\end{tabular}

